\title{
P09-05. Mechanism of HIV-I resistance to a monoclonal antibody that effectively targets the site of CD4 attachment $\mathrm{X} \mathrm{Wu}^{*}$, T Zhou, S O'Dell, RT Wyatt, PD Kwong and JR Mascola
}

Address: Vaccine Research Center, NIAID, NIH, Bethesda, MD, USA

* Corresponding author

from AIDS Vaccine 2009

Paris, France. 19-22 October 2009

Published: 22 October 2009

Retrovirology 2009, 6(Suppl 3):PII8 doi:10.I I86/I742-4690-6-S3-PII8

This abstract is available from: http://www.retrovirology.com/content/6/S3/PI I 8

(c) 2009 Wu et al; licensee BioMed Central Ltd.

\section{Background}

The region of HIV-1 envelope glycoprotein gp120 that engages its primary cellular receptor CD4, forms a site of vulnerability to neutralizing antibodies. The monoclonal antibody b12 exploits the conservation and accessibility of the CD4-binding site to neutralize many, though not all HIV-1 isolates.

\section{Methods}

To understand the basis of viral resistance to b12 neutralization, we used the atomic-level definition of b12-gp120 contact sites to study a panel of diverse circulating viruses. A combination of sequence analysis, computational modeling, and site-directed mutagenesis were used to determine the influence of amino-acid variants on binding and neutralization by b12.

\section{Results}

We found that several substitutions within the dominant b12-contact surface, called the CD4-binding loop, mediated b12 resistance and that these substitutions resided just proximal to the known CD4-contact surface. This explained how primary isolates of HIV-1 were able to evade b12 neutralization while retaining functional binding to CD4. In addition, some viruses were resistant to b12 despite minimal sequence variation at b12-contact sites. Such neutralization resistance could usually be reversed by alterations at residues thought to influence the quaternary configuration of the viral envelope spike.

\section{Conclusion}

Among circulating isolates of HIV-1, b12 resistance arises from a combination of sequence variation at key b12-contact residues, which are proximal to but not part of the CD4-contact surface, and alterations in the native configuration of the viral envelope spike, which serves to restrict b12 access. These data inform vaccine design by explaining how the virus can escape from neutralizing antibodies yet retain functional binding to its primary cellular receptor. Researchers may be able to use this information to design modifications of vaccine immunogens to better induce neutralizing antibodies to vulnerable regions of HIV-1. 